\title{
MicroRNA-494 inhibits nerve growth factor-induced cell proliferation by targeting cyclin D1 in human corneal epithelial cells
}

\author{
DAN WU $^{1 *}$, TINGTING QIAN ${ }^{2 *}$, JIAXU HONG $^{1}$, GANG LI $^{1}$, WEIYUN SHI ${ }^{3}$ and JIANJIANG XU ${ }^{1}$ \\ ${ }^{1}$ Department of Ophthalmology and Visual Science, Shanghai Eye, Ear, Nose and Throat Hospital, Shanghai Medical \\ College, Fudan University, Shanghai 200031; ${ }^{2}$ Department of Immunology and Biotherapy Research Center, \\ Shanghai Medical College, Fudan University, Shanghai 200032; ${ }^{3}$ Department of Ophthalmology, Shandong Eye \\ Hospital, Shandong Eye Institute, Shandong Academy of Medical Sciences, Jinan, Shandong 250021, P.R. China
}

Received June 8, 2016; Accepted May 15, 2017

DOI: $10.3892 / \mathrm{mmr} .2017 .7083$

\begin{abstract}
Nerve growth factor (NGF) is expressed in the human corneal epithelium and stroma. It is an efficient therapy for human corneal ulcers caused by neurotropic disease. However, little is known about the molecular mechanism of NGF in healing human corneal epithelial diseases. Numerous microRNAs (miRNAs) are expressed in the cornea and miRNAs have important roles in regulating corneal development. In the present study, novel miRNA regulators were demonstrated to be involved in NGF-induced human corneal epithelial cell (hCEC) proliferation. NGF treatment significantly downregulated the expression of miRNA-494 in hCECs in vitro. Furthermore, miRNA-494 increased G1 arrest in the immortalized human corneal epithelial cell (ihCEC) line and suppressed cell proliferation. Accordingly, bioinformatics programs and luciferase reporter assay demonstrated that miRNA-494 directly targeted cyclin D1 by binding to a sequence in the 3'-untranslated region. In addition, overexpression of miRNA-494 decreased both basal and NGF-induced cyclin D1 expression. NGF treatment partially suppressed miRNA-494 expression and restored cyclin D1 expression. Furthermore, co-transfection of miRNA-494 with the cyclin D1 ORF clone partially restored cyclin D1 mRNA and protein expression. These findings indicate that miRNA-494 and its target cyclin D1 may be a crucial axis for NGF in regulating the proliferation of hCEC. Specific modulation of miRNA-494 in hCEC could represent an attractive approach for treating cornea epithelial diseases.
\end{abstract}

Correspondence to: $\mathrm{Dr}$ Jianjiang $\mathrm{Xu}$, Department of Ophthalmology and Visual Science, Shanghai Eye, Ear, Nose and Throat Hospital, Shanghai Medical College, Fudan University, 83 Fenyang Road, Shanghai 200031, P.R. China

E-mail: jianjiangxu@126.com

*Contributed equally

Key words: human corneal epithelial cell, nerve growth factor, microRNA, cyclin D1, cell proliferation

\section{Introduction}

Nerve growth factor (NGF) belongs to the neurotrophin (NT) family. In addition to the two classes of well-known NGF transmembrane receptors, the high-affinity neurotrophin receptor neurotrophic receptor tyrosine kinase 1 (TrkA) and the low-affinity pan-NT receptor nerve growth factor receptor (p75NTR), discoidin domain receptor tyrosine kinase 1 (TrkE) was found to be a receptor of NGF $(1,2)$. The binding of a neurotrophin to its receptor induces dimerization and phosphorylation that initiates a signal transduction cascade and ultimately leads to gene transcription. NGF is expressed in the human corneal epithelium (3) and stroma (4), together with its two corresponding receptors, TrkA and p75NTR. NGF activates the TrkA signaling pathway and promotes cell survival and proliferation, whereas the activation of p75NTR can result in apoptosis (5). Furthermore, NGF supports stem cell self-renewal in corneal epithelial progenitor cells $(3,4)$, a phenomenon that has recently gained attention as an efficient therapy for human corneal ulcers caused by neurotropic disease (6).

MicroRNAs (miRNAs or miRs), a class of 19-25 nucleotide non-coding RNA molecules, negatively regulate the gene expression by binding to the 3'-untranslated region (3'-UTR) of mRNA, resulting in mRNA degradation or translational inhibition $(7,8)$. Since miRNA can induce gene silencing with only partial sequence homology, miRNAs have more than one target. miRNA is important in multistep cellular functions and biological processes, including cell differentiation, proliferation, and apoptosis (9). In studies of diseases of the cornea, miRNA provides new insights into corneal epithelium physiology processes. Overexpression of miRNA-31 downregulates hypoxia-inducible factor 1 alpha inhibitor in human corneal epithelial cells (hCECs), thereby decreasing cellular glycogen and influencing their energy stores (10). miRNA-145 acts on human endothelin converting enzyme, decreases the expression of ITGB8 and promotes corneal epithelium differentiation (11). miRNA-205 directly targets SH2-containing inositol phosphatase-2 (SHIP2): The high-miRNA-205/low-SHIP2 phenotype of corneal epithelial cells is an innate mechanism to regulate 
cell proliferation (12). In addition, numerous miRNAs are expressed in the cornea and have important roles in regulating corneal development $(13,14)$. Peng et al $(15)$ demonstrated that miRNA-103/107 can target the ribosomal kinase p90RSK2 and arrest cornea epithelial stem cells in G0/G1 stage, thereby contributing to a slow-cycling phenotype. Furthermore, miRNA-146a and miR-424 are involved in cornea epithelial cell migration and wound healing through targeting epidermal growth factor receptor and other signaling molecules such as interleukin-1 receptor-associated kinase 1 (16-19). These studies demonstrate the significance of miRNAs in corneal epithelial physiology.

In the present study, the miRNA signature in response to NGF treatment in hCECs was elucidated. These results indicated that NGF altered specific miRNA expression in hCECs, especially miRNA-494. miRNA-494, was downregulated in hCECs following NGF treatment, which decreased cyclin D1 expression, causing G1 arrest. Cyclin D1 was, furthermore, identified as a novel direct target of miRNA-494. Therefore, it appeared that miRNA-494 was an NGF-responsive miRNA in hCECs, which influenced NGF function in promoting corneal epithelial proliferation.

\section{Materials and methods}

Cell culture. hCECs were obtained from remaining eye tissues after the removal of the central corneal button for penetrating keratoplasty, at the eye bank of Shanghai Eye, Ear, Nose, and Throat Hospital (Shanghai, China). Cells were cultured as described in our previous study (20).

The immortalized human corneal epithelial cell (ihCEC) line was kindly provided by Dr Shi Wei-yun (Shandong Eye Hospital, Shandong Eye Institute, Shandong Academy of Medical Sciences, Jinan, China) and Professor Kaoru Araki-Sasaki (Osaka University, Osaka, Japan). The ihCEC line was maintained in DMEM/F12 medium (HyClone; GE Healthcare Life Sciences, Logan, UT, USA) supplemented with $10 \%$ fetal bovine serum (Gibco; Thermo Fisher Scientific, Inc., Waltham, MA, USA) and $1 \%$ penicillin/streptomycin. The cells were maintained in a humidified atmosphere at $37^{\circ} \mathrm{C}$ with $5 \% \mathrm{CO}_{2}$. The medium was changed every 3 days, and the cells were reseeded after reaching $80-90 \%$ confluence. The cells at passages 4-8 were used for experiments (21).

Immunofluorescence. ihCECs were seeded onto glass cover slips placed in a 24 well plate $\left(1 \times 10^{4}\right.$ cells/well $)$. Coverslips were fixed in $4 \%$ paraformaldehyde for $10 \mathrm{~min}$ at room temperature. Prior to permeabilization at $4^{\circ} \mathrm{C}$ for $20 \mathrm{~min}$ in $0.5 \%$ Triton X-100 (Sigma-Aldrich; Merck KGaA, Darmstadt, Germany), cells were washed 3 times in PBS. In order to avoid nonspecific binding, cells were treated with $10 \%$ fetal bovine serum (Gibco; Thermo Fisher Scientific, Inc.) at room temperature for $1 \mathrm{~h}$, after which cells were incubated with primary antibodies against cytokeratin 12 (CK12; 1:200; cat. no. sc-17099; Santa Cruz Biotechnology, Inc., Dallas, TX, USA) overnight at $4^{\circ} \mathrm{C}$. After 4 washes with PBS for 5 min each, cells were incubated with fluorescein isothiocyanate-conjugated anti-goat secondary antibody (1:200; cat. no. F7367; Sigma-Aldrich; Merck KGaA) for $45 \mathrm{~min}$. The cells were rinsed with PBS, then incubated with 4',6-diamidino-2-phenylindole (DAPI;
Sigma-Aldrich; Merck KGaA) at room temperature for $1 \mathrm{~min}$. ihCECs were analyzed by fluorescence microscopy.

Drug treatment. Following $24 \mathrm{~h}$ incubation, human recombinant NGF- $\beta$ (Sigma-Aldrich; Merck KGaA) diluted in PBS containing $0.1 \%$ bovine serum albumin, was added to the culture medium at a final concentration of $25 \mathrm{ng} / \mathrm{ml}$. The cells were then continuously incubated for $1 \mathrm{~h}$ at $37^{\circ} \mathrm{C}$. The control cells were incubated in fresh culture medium without the addition of NGF- $\beta$.

miRNA microarray analysis. The RNAs were obtained according to the TRIzol method. The cells were washed with cold 1X PBS 3 times, and the monolayer was covered with $1 \mathrm{ml}$ of TRIzol (Invitrogen; Thermo Fisher Scientific, Inc.) and lysed by repeated pipetting. Subsequently, the lysed samples were incubated on ice for $5 \mathrm{~min}$ and centrifuged for $15 \mathrm{~min}$ at $15,000 \mathrm{x} \mathrm{g}$ at $4^{\circ} \mathrm{C}$. The supernatants were transferred into new tubes and $200 \mathrm{ml}$ chloroform was added. The tubes were shaken vigorously by hand for $15 \mathrm{sec}$, and the mixture was incubated at $15-30^{\circ} \mathrm{C}$ for $2 \mathrm{~min}$. Subsequently, the chloroform-mixed samples were centrifuged for $15 \mathrm{~min}$ at $15,000 \mathrm{x} \mathrm{g}$ at $4^{\circ} \mathrm{C}$. The aqueous phase was transferred to other tubes and the RNA was precipitated from the aqueous phase by mixing with $500 \mathrm{ml}$ isopropyl alcohol for incubation at $15-30^{\circ} \mathrm{C}$ for $10 \mathrm{~min}$. The mixture was centrifuged for $30 \mathrm{~min}$ at $15,000 \mathrm{xg}$ at $4^{\circ} \mathrm{C}$ and the RNA precipitate formed a gel-like pellet on the side of the tube at the bottom. The gel-like pellet was acquired via removal of the supernatant and washed once with $1 \mathrm{ml} \mathrm{75 \%}$ ethanol, followed by centrifugation for $10 \mathrm{~min}$ at $10,000 \mathrm{x} \mathrm{g}$ at a temperature of $4^{\circ} \mathrm{C}$. The pellet was dried and dissolved in RNase-free water. The RNAs were sent to the MicroRNA Microarray Service (Gminix Biologic Science Co., Ltd, Shanghai, China), which used Affymetrix GeneChip miRNA Array.

Reverse transcription-quantitative polymerase chain reaction $(R T-q P C R)$. Total RNA was isolated from hCECs using TRIzol, according to the manufacturer's instructions. RNAs were reverse transcribed to cDNA with an RT-PCR system. cDNA for miRNA qPCR was synthesized using a One Step PrimeScript ${ }^{\circledR}$ miRNA cDNA Synthesis kit (cat. no. D350A; Takara Biotechnology Co., Ltd., Dalian, China). The reaction conditions were as follows: $37^{\circ} \mathrm{C}$ for $60 \mathrm{~min}$, followed by a final step of $37^{\circ} \mathrm{C}$ for 5 sec. cDNA for mRNA real-time PCR was synthesized using a PrimeScript ${ }^{\mathrm{TM}} \mathrm{RT}$ reagent kit with gDNA Eraser (cat. no. RR047A; Takara Biotechnology Co., Ltd.). The following conditions were used: gDNA Eraser at $42^{\circ} \mathrm{C}$ for $2 \mathrm{~min}$, cDNA synthesis at $37^{\circ} \mathrm{C}$ for $15 \mathrm{~min}$, followed by $85^{\circ} \mathrm{C}$ for $5 \mathrm{sec}$. SYBR ${ }^{\circledR}$ Premix Ex Taq ${ }^{\mathrm{TM}}$ II Real-Time PCR kit (cat. no. DRR081A; Takara Biotechnology Co., Ltd.) was used with the ABI ViiA7 Real-Time PCR System (Thermo Fisher Scientific, Inc.) for qPCR analysis, which was performed as follows: Pre-denaturation at $95^{\circ} \mathrm{C}$ for $30 \mathrm{sec}$, 40 cycles of $95^{\circ} \mathrm{C}$ for $5 \mathrm{sec}$, followed by $60^{\circ} \mathrm{C}$ for $34 \mathrm{sec}$. The PCR products were stored at $4^{\circ} \mathrm{C}$. The primers used are listed in Table I. The universal-miRNA qPCR primer (cat. no. D350) and miRNA-15, miRNA-184, miRNA-320c, U6RNA primers were purchased from Takara Biotechnology Co., Ltd. The $\Delta \Delta \mathrm{Cq}$ method (22) for relative quantitation of gene and miRNA expression was used to determine cyclin D1 
Table I. Reverse transcription - quantitative polymerase chain reaction primer sequences.

\begin{tabular}{ll}
\hline Target gene & \multicolumn{1}{c}{ Primer sequence } \\
\hline U6 & F-CAAATTCGTGAAGCGTT \\
& R-TCAACTGGTGTCGTGG \\
Cyclin D1 & F-AGCCATGGAACACCAGCTC \\
GAPDH & R-GCACCTCCAGCATCCAGGT \\
miRNA-494 & F-TGCACCACCAACTGCTTAGC \\
& F-TGAAACATACACGGGAAACCTC \\
miRNA-1305 & R-Universal-miRNA qPCR primer \\
& F-TTTTCAACTCTAATGGGAGAGA \\
& R-Universal-miRNA qPCR primer
\end{tabular}

miRNA, microRNA; F, forward primer; R, reverse primer.

and miRNA-494 expression levels according to ABi protocol. U6 RNA and GAPDH were used to normalize the relative abundance of miRNA-494 and cyclin D1, respectively.

Prediction of the target gene of miRNA-494. Gene Ontology (GO; www. geneontology.org) analysis was used to select significant GO. GO may be used to analyze the function of interesting genes in biological processes, cellular components and molecular functions (23). mirBase (www.microrna .org/microrna/home.do), miRWalk (zmf.umm.uni-heidelberg .de/apps/zmf/mirwalk/index.html) and targetScan (www.targetscan.org/vert_71) bioinformatics software was used to predict the target gene of miRNA-494.

Western blot analysis. The cells were lysed in radioimmunoprecipitation assay buffer supplemented with protease inhibitors (Complete, Mini, EDTA-free; Roche Applied Science, Penzburg, Germany) and Phosphatase Inhibitor Cocktails 1 and 2 (Sigma-Aldrich; Merck KGaA) at $4^{\circ} \mathrm{C}$ for $30 \mathrm{~min}$. The cells were then centrifuged at $15,000 \mathrm{x}$ g for $20 \mathrm{~min}$ at $4^{\circ} \mathrm{C}$ to achieve a clear state. Cell lysates were separated by $10 \%$ SDS-PAGE and transferred onto Hybond-P polyvinylidene difluoride membranes (Merck KGaA). Membranes were blocked in 5\% skimmed milk at room temperature, for $30 \mathrm{~min}$, then incubated overnight at $4^{\circ} \mathrm{C}$ with mouse anti-cyclin D1 (1:1,000; $37 \mathrm{kDa}$; cat. no. SC-8396; Santa Cruz Biotechnology, Inc., ) or rabbit anti-GAPDH (1:5,000; 37 kDa; cat. no. AB-P-R 001; Miao Tong Biological Science \& Technology Co., Ltd., Shanghai, China) primary antibodies. Membranes were then incubated at room temperature for $1 \mathrm{~h}$ with anti-mouse $(1: 2,000$; cat. no. 7076; Cell Signaling Technology, Inc., Danvers, MA, USA) or anti-rabbit immunoglobulin $\mathrm{G}$ horseradish peroxidase-conjugated secondary antibodies (1:2,000; cat. no. 7074; Cell Signaling Technology, Inc.), respectively. Immune reactive proteins were visualized using Enhanced Chemiluminescence Plus Western Blotting Detection reagents (GE Healthcare Life Sciences) and the LAS4000 luminescent image analyzer (Kodak, Rochester, NY, USA). Densitometric analysis of band intensity was performed using Carestream Molecular Imaging Software Standard Edition 5.0.2.30 (Kodak).
Virus and cyclin DI ORF clone transfection. The lentiviral vector pGIPZ-GFP-miR-494 or negative control pGLV3-GFP-NC and lentiviral packaging plasmids (SunBio Medical Biotechnology, Shanghai, China) were co-transfected into 293FT packaging cells. The sequence of miR-494 was as follows: CAGTGCCATGTAGATTCGGGGAATCTT CCTGGAGGTGACACCAACATCGGCGAAGATTCGGCA GTTCTGTTTTGATTTTTTTTGTTTGTTTTTTGATCAGT GCTAATCTTCGATACTCGAAGGAGAGGTTGTCCGTG TTGTCTTCTCTTTATTTATGATGAAACATACACGGGA AACCTCTTTTTTAGTATCAAATCCCACCCTGGAGGC ACTTCCTGTTCCTGATGCAGCCTTCAGGGAGGGACG TTGCCGGCTCCACTCTCGGTAGGCGCAAGCGAGGCT GACAGCGTGCCATGC. The negative control sequence was as follows: TCTCGCTTGGGCGAGAGTAAGTAGTGAAGC CACAGATGTACTTACTCTCGCCCAAGCGAGA. The virus-containing supernatant was harvested and filtered $72 \mathrm{~h}$ post-transduction, then used to infect the ihCEC line with Polybrene ${ }^{\circledR}$ (Sigma-Aldrich; Merck KGaA) at a final concentration of $5 \mu \mathrm{g} / \mathrm{ml}$. Following $24 \mathrm{~h}$ of transfection, the cell culture medium was replaced with fresh complete medium and the ihCEC line was incubated for an additional 48-72 $\mathrm{h}$ prior to determining the expression of green fluorescent protein (GFP). Following flow-cytometer (Epics Altra; Beckman Coulter, Inc., Brea, CA, USA) selection for GFP (+) cells, the stable clones were obtained. The analysis software used was Expo32 V1.2 Analysis Multicycle for Windows (Beckman Coulter, Inc.). Furthermore, pGIPZ-GFP-miR-494 ihCEC line was transfected with a cyclin D1 ORF clone in a pcDNA3.1 vector (GeneCopoeia, Inc., Rockville, MD, USA) using Lipofectamine 2000 (Invitrogen; Thermo Fisher Scientific, Inc.) according to the manufacturer's protocol. The cells were cultured for $72 \mathrm{~h}$ following transfection.

Cell cycle analysis. A total of $5 \times 10^{6}$ cells were harvested, washed twice with cold PBS, fixed overnight with $75 \%$ cold ethanol at $4^{\circ} \mathrm{C}$, then washed with PBS again. Cells were then resuspended in $0.2 \%$-Triton X-100 containing $50 \mu \mathrm{g} / \mathrm{ml}$ propidium iodide (PI) and $100 \mu \mathrm{g} / \mathrm{ml}$ RNase at $4^{\circ} \mathrm{C}$ for $30 \mathrm{~min}$ in the dark. The pGIPZ-GFP-miR-494 or pGIPZ-GFP-NC ihCEC line was analyzed on FACS Calibur ${ }^{\mathrm{TM}}$ Flow Cytometer and Cell Quest ${ }^{\mathrm{TM}}$ software (BD Biosciences, San Diego, CA).

3'-UTR Construct. mirBase, miRWalk and targetScan bioinformatics software was used to predict the binding site between cyclin D1 and miRNA-494. The cyclin D1 3' UTR contains a putative binding site for miRNA-494 with the seed region at 1345-1364. The wild-type or mutant 3'-UTR fragment was cloned into the pmiRGLO reporter vector (Promega Corporation, Madison, WI, USA): The wild-type construct contained a $300 \mathrm{bp}$ truncated portion of the wild-type 3' UTR, including the seed sequence; the mutant construct contained the same $300 \mathrm{bp}$ truncated portion of the wild-type 3' UTR, but with the sequence at 1357-1363 -ATGTTTC-replaced by -AACTTAG-.

Luciferase reporter assay. 293T cells grown in 6-well plates $\left(1.0 \times 10^{5}\right.$ cells per well) were harvested for assays $48 \mathrm{~h}$ after transfection with pcDNA6.2-GW/miRNA-494 and pmiRGLO-cyclin D1-3' UTR vectors (Promega Corporation). Lipofectamine 2000 reagent (Invitrogen; Thermo Fisher 
Table II. Differential miRNA expression in HCEC following NGF treatment.

\begin{tabular}{|c|c|}
\hline miRNA & Fold change (NGF/control) \\
\hline \multicolumn{2}{|l|}{ Upregulated } \\
\hline miR-3179 & 5 \\
\hline $\operatorname{miR}-598$ & 2 \\
\hline $\operatorname{miR}-634$ & 24 \\
\hline miR-129-3p & 15 \\
\hline $\operatorname{miR}-211$ & 31 \\
\hline $\operatorname{miR}-3115$ & 2 \\
\hline miR-582-5 & 9 \\
\hline let- $7 b$ & 29 \\
\hline miR-129 & 22 \\
\hline $\operatorname{miR}-1246$ & 4 \\
\hline $\operatorname{miR}-17$ & 2 \\
\hline $\operatorname{miR}-202$ & 28 \\
\hline $\operatorname{miR}-297$ & 2 \\
\hline $\operatorname{miR}-615-5 p$ & 4 \\
\hline $\operatorname{miR}-1181$ & 7 \\
\hline $\operatorname{miR}-548 b-3 p$ & 3 \\
\hline miR-146a & 6 \\
\hline miR-199b-5p & 24 \\
\hline $\operatorname{miR}-223$ & 10 \\
\hline $\operatorname{miR}-495$ & 3 \\
\hline $\operatorname{miR}-1183$ & 25 \\
\hline miR-515-5p & 13 \\
\hline miR-103 & 18 \\
\hline $\operatorname{miR}-1825$ & 21 \\
\hline $\operatorname{miR}-18 b$ & 2 \\
\hline $\operatorname{miR}-217$ & 4 \\
\hline miR-524-5p & 16 \\
\hline \multicolumn{2}{|l|}{ Downregulated } \\
\hline miR-1182 & 2 \\
\hline $\operatorname{miR}-1202$ & 4 \\
\hline $\operatorname{miR}-1208$ & 11 \\
\hline miR-1268 & 2 \\
\hline $\operatorname{miR}-1275$ & 2 \\
\hline $\operatorname{miR}-1471$ & 4 \\
\hline $\operatorname{miR}-15 a$ & 19 \\
\hline miR-188-5p & 8 \\
\hline miR-204 & 3 \\
\hline miR-220b & 2 \\
\hline $\operatorname{miR}-3127$ & 5 \\
\hline miR-31-star & 2 \\
\hline miR-337-5p & 2 \\
\hline miR-889 & 2 \\
\hline miR-1207-5p & 12 \\
\hline miR-1225-5p & 3 \\
\hline miR-494 & 20 \\
\hline miR-1305 & 32 \\
\hline $\operatorname{miR}-150$ & 24 \\
\hline miR-184 & 10 \\
\hline miR-19b & 18 \\
\hline miR-219-2-3p & 3 \\
\hline miR-30b & 5 \\
\hline miR-3168 & 2 \\
\hline miR-320c & 31 \\
\hline miR-342-5p & 2 \\
\hline
\end{tabular}

Table II. Continued.

\begin{tabular}{lr}
\hline miRNA & Fold change (NGF/control) \\
\hline miR-513a-5p & 33 \\
miR-516a-5p & 2 \\
miR-555 & 2 \\
miR-575 & 4 \\
miR-630 & 5 \\
miR-641 & 9 \\
miR-647 & 3 \\
miR-662 & 4 \\
miR-765 & 5 \\
miR-513b & 24 \\
miR-543 & 3 \\
miR-568 & 2 \\
miR-671-5p & 11 \\
miR-939 & 3 \\
miR-660 & 2 \\
miR-1274b & 2 \\
miR-483-3p & 2 \\
miR-646 & 16 \\
miR-4297 & 2 \\
miR-4260 & 2 \\
miR-638 & 2 \\
miR-371-5p & 2 \\
miR-370 & 10 \\
miR-601 & 2 \\
\hline & \\
&
\end{tabular}

miRNA, microRNA; miR, microRNA; HCEC, human corneal epithelial cell; NGF, nerve growth factor.

Scientific, Inc.) was used for the corresponding NC. The firefly and Renilla luciferase activities were measured using a dual-luciferase reporter assay system (Promega Corporation) with a microplate luminometer, and each sample's luciferase activity was normalized to that of Renilla.

Statistical analysis. Each experiment was performed in triplicate. Data are presented as the mean \pm standard deviation. Two group comparisons were analyzed using Student's t-tests; comparisons between $\geq 3$ groups were performed using analysis of variance followed by Tukey's post hoc test. Analyses were performed using SPSS software, version 19.0 (IBM Corp., Armonk, NY, USA). P<0.05 was considered to indicate a statistically significant difference.

\section{Results}

Differential miRNA expression in hCECs following NGF treatment. To identify the expression of miRNA in hCECs exposed to NGF, an Affymetrix GeneChip miRNA Array was performed in hCECs following NGF treatment. Differential expression was defined using a cut-off value of 2 -fold change. A total of 27 miRNAs were upregulated and 50 miRNAs were downregulated in NGF-treated hCECs (Table II). Since the expression of cyclin D1 is increased following NGF treatment in hCECs (20), whereas miRNA had a negative regulatory 


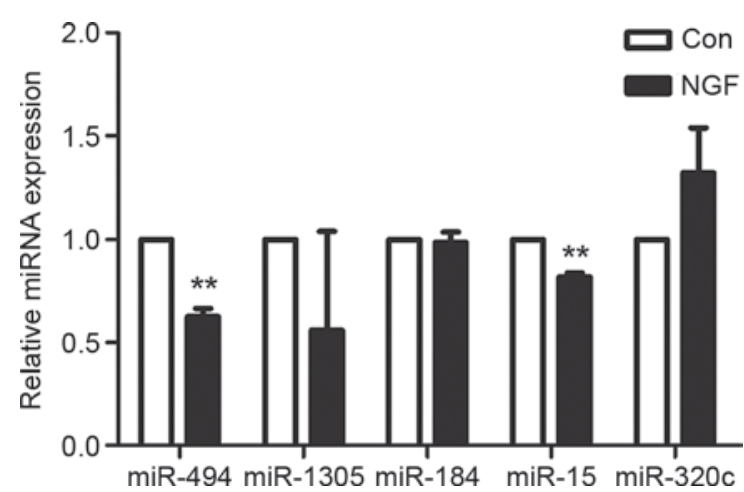

Figure 1. miRNA-494 expression is repressed by NGF treatment in hCEC. Reverse transcription-quantitative polymerase chain reaction analysis demonstrated the expression levels of miRNA-494, miRNA-1305, miRNA-184, miRNA-15 and miRNA-320c in human corneal epithelial cells following $1 \mathrm{~h}$ treatment with 0 or $25 \mathrm{ng} / \mathrm{ml} \mathrm{NGF}$ relative to expression of U6 control. ${ }^{* *} \mathrm{P}<0.01$ vs. untreated control. miRNA, microRNA; NGF, nerve growth factor; Con, untreated control.

effect on its target genes (24), the present study focused on the downregulated miRNAs. GO analysis was performed on the downregulated miRNAs, and 5 miRNAs (miRNA-494, miRNA-1305, miRNA-15, miRNA-18, and miRNA-320c), which functioned on cell proliferation, were selected for further investigation. The microarray results were then validated by RT-qPCR. Consistent with the microarray data, miRNA-494, miRNA-1305 and miRNA-15 were demonstrated to be downregulated in NGF-treated hCECs to $62.1 \%(\mathrm{P}=0.005), 56.0 \%$ $(\mathrm{P}=0.062)$, and $81.7 \%(\mathrm{P}=0.003)$ of the levels of untreated controls, respectively (Fig. 1). The effect on miRNA-494 was the most significant, therefore, miRNA-494 was chosen as a candidate for further study.

Overexpression of miRNA-494 by transfecting lentivirus pGIPZ-GFP-miR-494 in the ihCEC line. ihCECs were demonstrated to express CK12, which is a biomarker for the corneal epithelium (Fig. 2). The ihCEC line was transfected with lentivirus pGIPZ-GFP-miR-494. The negative control (NC) received pGLV3-GFP-NC (Fig. 3A and B). Flow cytometry was utilized after $72 \mathrm{~h}$ to enable sorting of the GFP-positive cells to establish the pGIPZ-GFP-miR-494 ihCEC and pGLV3-GFP-NC ihCEC lines, which contained GFP (+) cells up to $98 \%$ (Fig. 3C). The expression of miRNA-494 was 3.60 times greater in the pGIPZ-GFP-miR-494 ihCEC line than in the NC line $(\mathrm{P}<0.001 ;$ Fig. 3D).

miRNA-494 increases G0/G1 arrest in the ihCEC line. To investigate the role of miRNA-494 in the ihCEC line, the cells were treated with NGF and the cell cycle distribution analyzed by flow cytometry (Fig. 4A). Overexpression of miRNA-494 increased the cell number in the G1 phase, compared to the pGLV3-GFP-NC ihCEC lines (Fig. 4B). NGF treatment, which partially reversed the negative effect of the miRNA-494, promoted cell cycle progression by decreasing cell distribution in the G1 phase (Fig. 4B). Overall, these results suggested that miRNA-494 inhibited NGF-induced proliferation by inhibiting cell cycle progression from the G0/G1 phase into the $\mathrm{S}$ phase in the ihCEC line.
miRNA-494 directly targeted the cyclin D1 gene. To clarify the mechanism by which miRNA-494 suppressed cell proliferation, we first applied three bioinformatics prediction programs (miRanda, miRWalk, and TargetScan) to predict the potential target of miRNA-494. A binding site between miRNA-494 and cyclin D1 (gene ID: 595) was identified. As presented in Fig. 5A, the 3'-UTR domain of the cyclin D1 mRNA was demonstrated to be partially complementary to miRNA-494. A luciferase reporter system in which the wild-type (WT) or mutant (MUT) cyclin D1 3'-UTR was cloned into a luciferase expression vector was then utilized. The data demonstrated that miRNA-494 significantly inhibited the luciferase activity of cyclin D1 3'-UTR wild type in the 293T cells $(\mathrm{P}<0.001$; Fig. 5B, white bars), whereas it had no significant effect on the mutant cells ( $\mathrm{P}>0.05$; Fig. 5B, black bars). Collectively, these results demonstrated that miRNA-494 directly targeted cyclin D1 mRNA by binding to its 3'-UTR.

miRNA-494 expression is decreased and cyclin D1 expression is increased by treatment with NGF. Cyclin D1 is important in cell cycle progression (25). To further substantiate the role of miRNA-494 in hCEC cell proliferation following exposure to NGF, miRNA-494 and cyclin D1 expression was examined in response to NGF. As determined by RT-qPCR analysis, in untreated cells, miRNA-494 was significantly overexpressed in the pGIPZ-GFP-miR-494 ihCEC line compared with the pGIPZ-GFP-NC ihCEC line ( $\mathrm{P}<0.001$; Fig. 6A). However, this effect was significantly attenuated by treatment with NGF (Fig. 6A, black bars). Cyclin D1 expression was upregulated by treatment with NGF (Fig. 6B, white vs. white bars and black vs. black bars). Overexpression of miRNA-494 decreased NGF-induced cyclin D1 mRNA (Fig. 6B) and protein expression (Fig. 6C), as demonstrated by RT-qPCR and western blot analysis, respectively. Furthermore, transfection of cyclin D1 ORF clone in the pGIPZ-GFP-miR-494 ihCEC line resulted in upregulation of cyclin D1 mRNA (Fig. 7A, 2nd vs. 3rd bars) and protein expression (Fig. 7B, 2nd vs. 3rd lanes). These changes demonstrated the specific functions of miRNA-494, in mediating the expression of the cell cycle-associated gene cyclin D1 and hCEC proliferation.

\section{Discussion}

Although many studies have focused on the role of NGFinhealing human corneal epithelial diseases (26), the molecular mechanism remained elusive. In the present study, miRNA-494 was demonstrated to be significantly downregulated in NGF-treated hCECs and was demonstrated to target cyclin D1 by binding to its 3'-UTR. Overexpression of miRNA-494 confirmed its anti-proliferation function by attenuating cyclin D1 expression and inducing G1 arrest in vitro. In order to further confirm the possible link between miRNA-494 and cyclin D1, cyclin D1 ORF clone was transfected into the pGIPZ-GFP-miR-494 ihCEC line and cyclin D1 expression was investigated. NGF treatment decreased the expression of miRNA-494 and restored cyclin D1 expression, leading to hCEC proliferation. In our previous study, we demonstrated that NGF regulated hCEC proliferation via the phosphoinositide 3-kinase $(\mathrm{PI} 3 \mathrm{~K}) /$ protein kinase $\mathrm{B}(\mathrm{Akt})$ and mitogen-activated protein kinase (MAPK)/extracellular signal-regulated kinase 


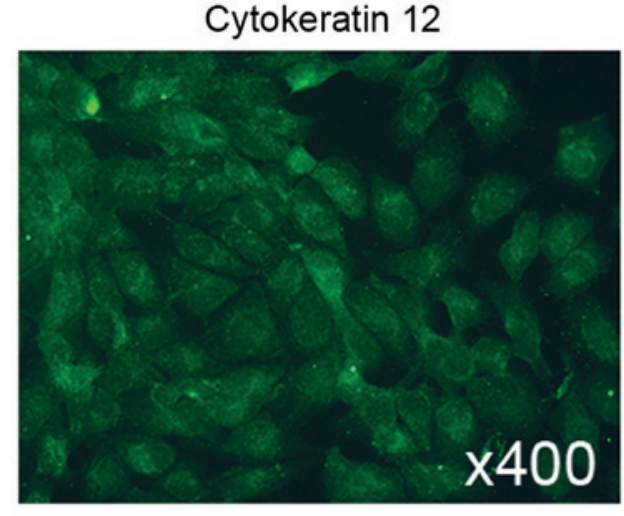

DAPI

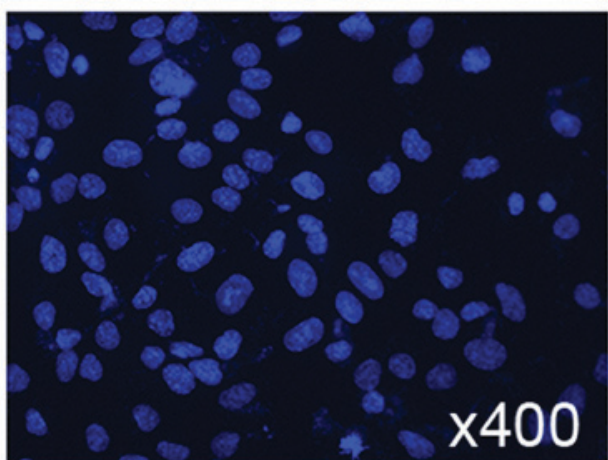

Merge

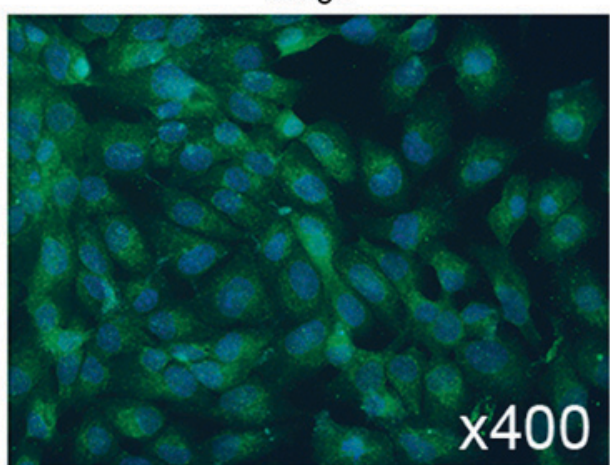

Figure 2. Immunofluorescence analysis of cytokeratin 12 (green) and DAPI (blue) in immortalized human corneal epithelial cells.

(ERK) signaling pathways. Furthermore, this research provides cognate evidence that miRNA-494 and its target gene, cyclin D1, could be a new crucial axis for NGF in regulating the proliferation of hCEC and treating corneal epithelial cell diseases (Fig. 8).

The human cornea produces and stores NGF at a concentration of $1,154 \pm 376 \mathrm{pg} / \mathrm{mg}$ under normal physiological conditions (21). Following the introduction of a lesion to corneal tissue, the concentration of NGF increased to a maximum concentration of $3,010 \pm 284 \mathrm{pg} / \mathrm{mg} 48 \mathrm{~h}$ after injury (27). NGF not only stimulates corneal epithelial proliferation in vivo and in vitro (28), but also helps to maintain limbal epithelial stem cells $(27,29)$. Endogenous NGF accelerates the corneal epithelial healing progress following cataract surgery $(26,29,30)$, and topical administration of NGF enhances the neurotropic corneal ulceration healing process (31-33) in normal and diabetic patients (28). NGF promotes corneal wound healing by upregulating corneal sensitivity and improving tear function (29). Inhibiting the pathway of endogenous NGF by
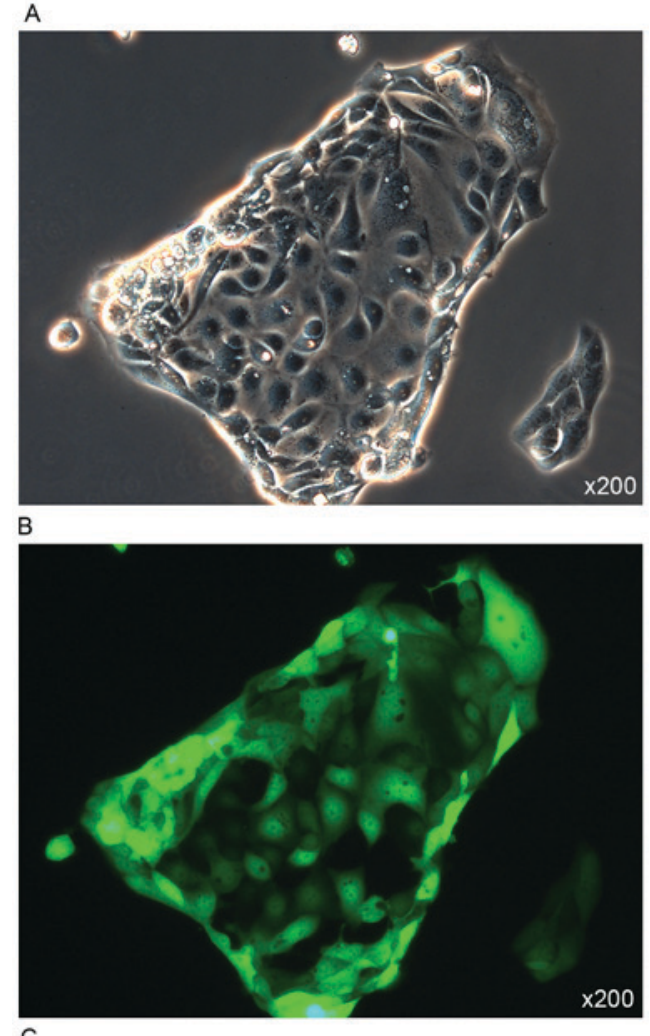

C
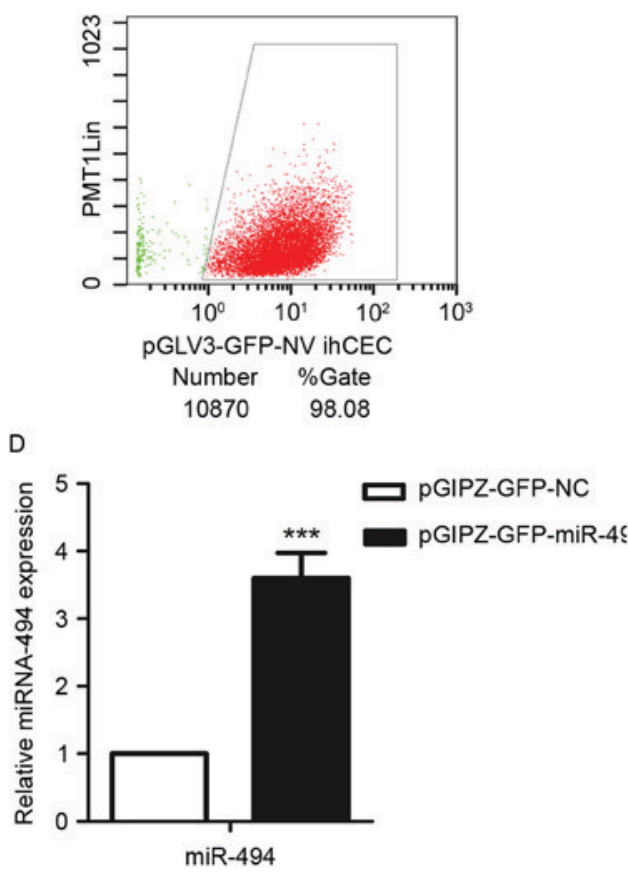

Figure 3. Overexpression of miRNA-494 in lentivirus pGIPZ-GFP-miR-494 ihCECs. The lentivirus pGIPZ-GFP-miR-494 ihCEC line was examined using (A) phase contrast microscopy and (B) fluorescent microscopy. (C) Flow cytometry was used to sort the GFP (+) cells to establish the pGIPZ-GFP-miR-494 ihCEC line and the pGLV3-GFP-NC ihCEC line, which contained the GFP (+) cells at concentrations up to $98 \%$. (D) miRNA494 expression in the pGIPZ-GFP-miR-494 and pGIPZ-GFP-NC ihCEC lines was measured using reverse transcription-quantitative polymerase chain reaction, with quantification relative to the U6 control. ${ }^{* * *} \mathrm{P}<0.001$ vs. pGLV3-GFP-NC. miRNA, microRNA; ihCEC, immortalized human corneal epithelial cell; GFP, green fluorescent protein; NC, negative control.

Ab-NGF or NGF mutational receptor suspends the epithelial healing process and results in corneal opacification $(34,35)$. 

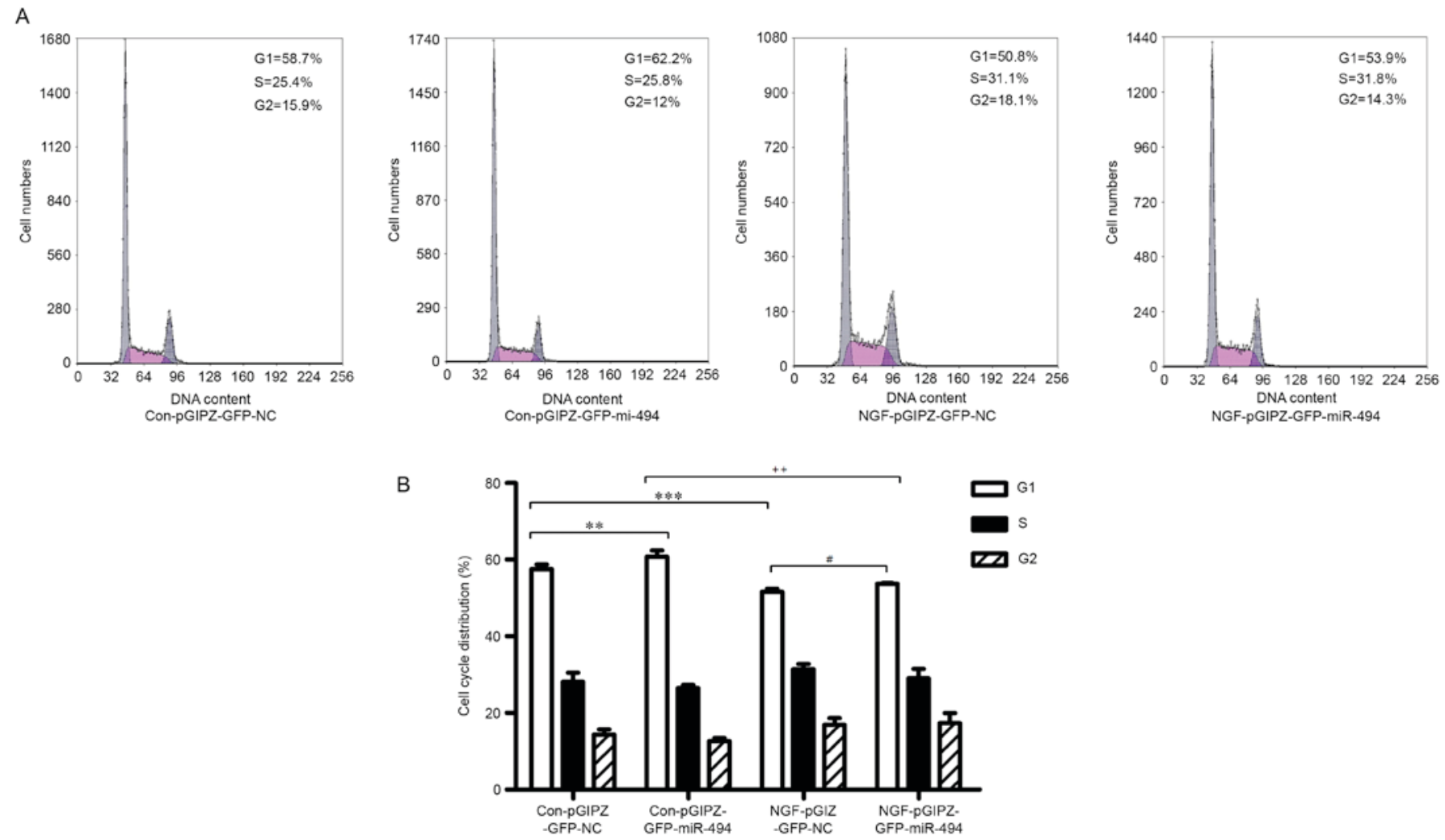

Figure 4. miRNA-494 increases G1 arrest. The ihCEC line was transfected with pGIPZ-GFP-miR-494 or pGIPZ-GFP-NC, treated with 0 (con) or $25 \mathrm{ng} / \mathrm{ml}$ NGF for $1 \mathrm{~h}$. (A) Cell cycle analysis was then performed and (B) the percentage of cells in each cell cycle phase was calculated. ${ }^{*} \mathrm{P}<0.05,{ }^{* * *} \mathrm{P}<0.01,{ }^{* * * *} \mathrm{P}<0.001$, ${ }^{\#} \mathrm{P}<0.05$ and ${ }^{++} \mathrm{P}<0.01$, as indicated by brackets.

A

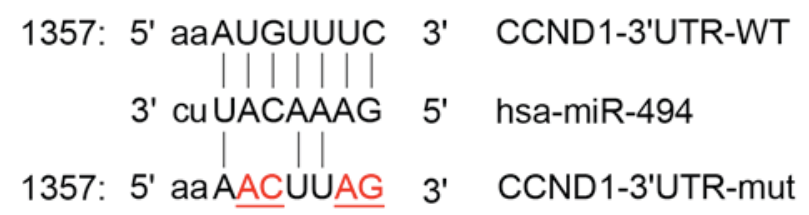

B
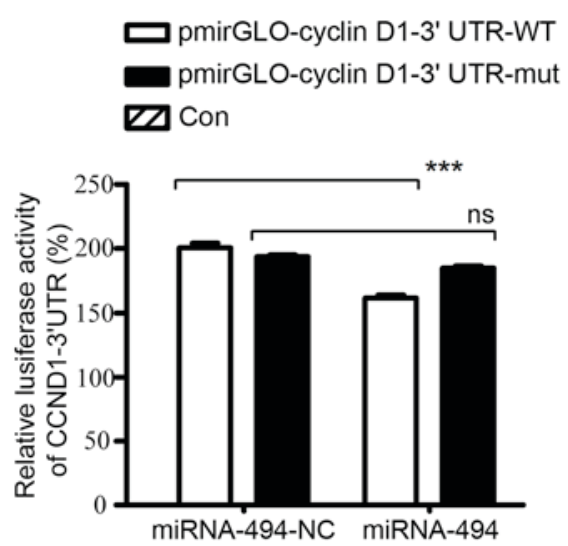

Figure 5. miRNA-494 directly targets the cyclin D1 gene. (A) Putative binding site of miRNA-494 and WT cyclin D1 3'-UTR, and mutated cyclin D1 3'-UTR binding site in which mutated bases are shown in red and underlined. (B) Luciferase reporter assay of 293T cells transfected with pmiRGLO-cyclin D1-3 UTR-WT or pmiRGLO-cyclin D1-3' UTR-mut together with miRNA-494 or NC. ${ }^{* * *} \mathrm{P}<0.001$. miR, microRNA; hsa, Homo sapiens; WT, wild type; UTR, untranslated region; mut, mutated; NC, negative control; ns, not significant.

Although many studies have investigated the function of NGF on hCEC proliferation, the mechanism has remained inconclusive.

miRNAs have previously been recognized as regulators of cell proliferation during NGF treatment. Zhang et al (36) reported that expression of Rattus norvegicus-miR-541 was downregulated by NGF stimulation in PC12 cells and that it targeted Synapsin-I, leading to neuritogenesis. Furthermore, miRNA-221 and miRNA-222 were upregulated by NGF in
PC12 cells (33). Thus far, the role of miRNA in NGF-induced hCEC proliferation had not been described. To the best of our knowledge, the present study demonstrates for the first time that miRNA-494 is an NGF-responsive miRNA in hCEC proliferation.

miRNA-494, which is located on chromosome 14q32.31, has profound impacts on many biological processes. It has been reported to regulate both anti-proliferation and pro-proliferation proteins. For instance, in human hepatocellular carcinoma, 

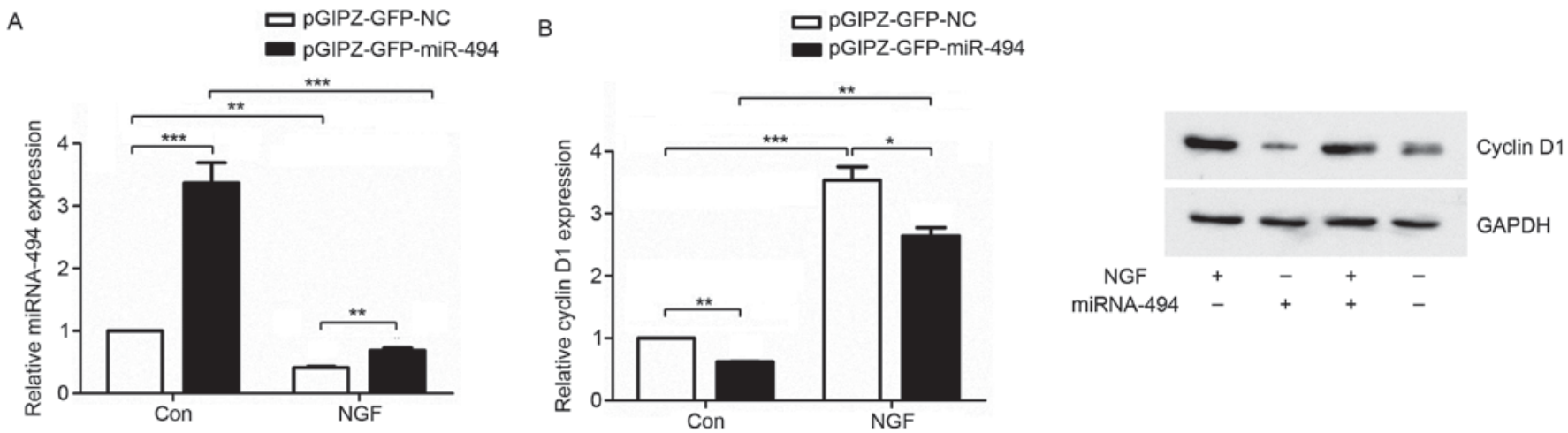

Figure 6. miRNA-494 is NGF-responsive and overexpression of miRNA-494 decreases cyclin D1 expression. (A) RT-qPCR was performed to determine the expression of miRNA-494. Transfecting pGIPZ-GFP-miR-494 caused the miRNA-494 levels to increase compared with transfection with pGIPZ-GFP-NC, whereas NGF treatment attenuated the miRNA-494 expression. (B) Overexpression of miRNA-494 decreased both cyclin D1 mRNA and protein expression in ihCECs, as demonstrated by RT-qPCR and western blot analysis, respectively. NGF treatment inhibited miRNA-494 expression and increased cyclin D1 expression. U6 was used as an internal control for RT-qPCR and GAPDH was used as an internal control for western blots. ${ }^{*} \mathrm{P}<0.05$, ${ }^{* *} \mathrm{P}<0.01$ and ${ }^{* * * *} \mathrm{P}<0.001$, as indicated by brackets. miRNA, microRNA; NGF, nerve growth factor; RT-qPCR, reverse transcription-quantitative polymerase chain reaction; NC, negative control; ihCECs, immortalized human corneal epithelial cells.

A

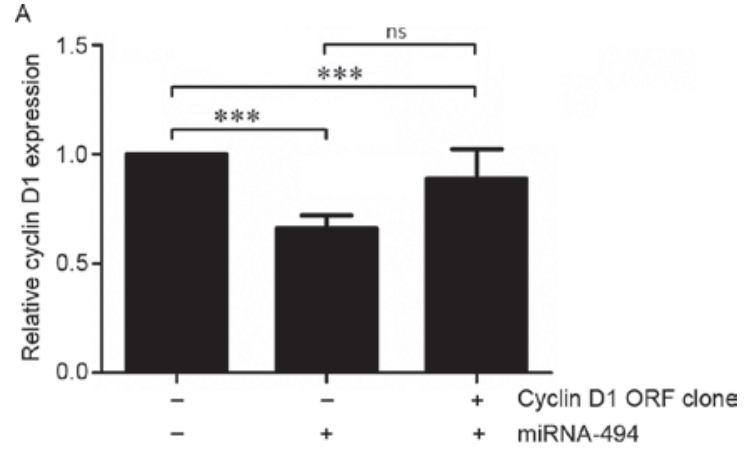

B

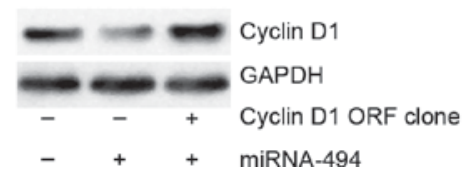

Figure 7. Cyclin D1 ORF clone upregulates cyclin D1 expression in pGIPZ-GFP-miR-494 ihCECs. ihCECs were transfected with pGIPZ-GFP-miR-494 or cyclin D1 ORF clone. Post-transfection (72 h), cyclin D1 (A) mRNA and (B) protein expression levels were determined by RT-qPCR and western blot analysis, respectively. Cyclin D1 ORF clone rescued cyclin D1 expression in pGIPZ-GFP-miR-494 ihCECs. U6 was used as an internal control for RT-qPCR and GAPDH was used as an internal control for western blots. ${ }^{* * *} \mathrm{P}<0.001$. ORF, open reading frame; miRNA, microRNA; ihCECs, immortalized human corneal epithelial cells; RT-qPCR, reverse transcription-quantitative polymerase chain reaction; ns, not significant.

increasing miRNA-494 expression promotes cell proliferation by advancing the G1/S cell cycle transition and targeting the mutated genes in colorectal cancer tumor suppressor (37). However, Kim et al (38) demonstrated that miRNA-494 represses gastrointestinal stromal tumor by negatively regulating KIT, an oncogenic tyrosine kinase. Furthermore, miRNA-494 was shown to target insulin like growth factor 2 mRNA binding protein 1 to suppress cell proliferation in A549 cells (39). The present study investigated the function of miRNA-494 in hCECs and demonstrated that miRNA-494 was downregulated in NGF-treated hCECs. Furthermore, ectopic miRNA-494 suppressed cell proliferation by inhibiting cyclin D1 expression, but this anti-proliferative activity was partially

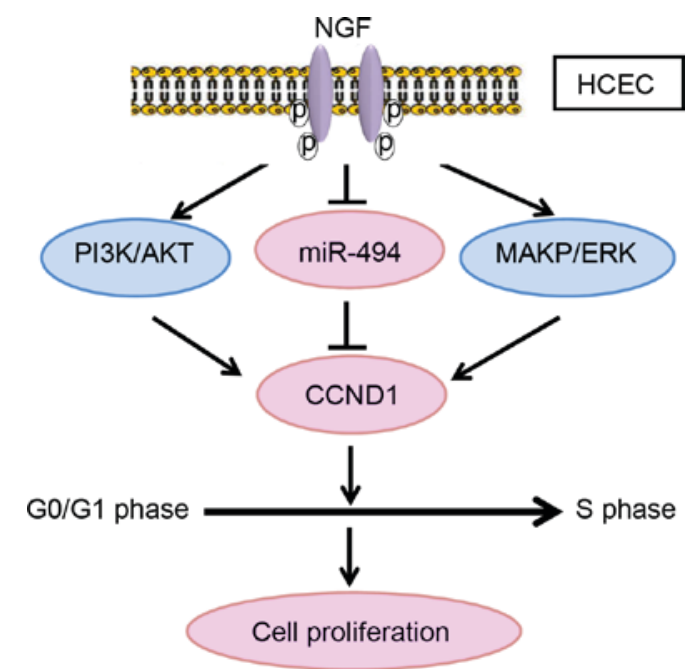

Figure 8. Model of NGF regulation of hCEC proliferation via PI3K/Akt and MAPK/ERK signaling pathways and miR-494 and cyclin D1. NGF, nerve growth factor; hCEC, human corneal epithelial cell; PI3K, phosphoinositide 3-kinase; Akt, protein kinase B; MAPK, mitogen-activated protein kinase; ERK, extracellular signal-regulated kinase; miR, microRNA; CCND1, cyclin D1.

reversed by NGF treatment. This could be explained by the following: one miRNA could regulate approximately 200 kinds of mRNA due to the allowance of a mismatched base pair with mRNA (40). Therefore, miRNA-494 might function in either a pro-proliferation or anti-proliferation manner according to the cellular environment and cell-specific targets. Although the present study indicated that the downregulation of miRNA-494 was associated with NGF treatment in hCECs, little is known about the mechanism of the regulation of miRNA-494 expression; this should be examined in future studies.

Several miRNA-494 targets have been recently identified in various cellular systems, including activating transcription factor 3 (41), phosphatase and tensin homolog (42), Bcl-2-like protein 11 (43), nucleolin (44) and solute carrier family 26 member 3 (45). In addition, miRNA-494 was 
reported to target mitochondrial transcription factor $\mathrm{A}$ and Forkhead box j3 in murine myoblast C2C12 cells (46). The present study identified cyclin D1 as a novel target of miRNA-494 in hCEC proliferation. Cyclin D1, which is a member of the D-type cyclins (D1, D2, and D3) family, interacts with cyclin-dependent kinase 4 (CDK4) $(47,48)$ to form a cyclin D1/CDK4 complex. The activation of CDK4 promotes cell cycle progression from $\mathrm{G} 1$ to $\mathrm{S}$ phase $(49,50)$ through phosphorylating substrates and transcription factors, which have roles in proliferation and differentiation. Cyclin D1 is regulated by numerous miRNAs, including Homo sapiens (hsa)-miR-638 (51), hsa-miR-425, hsa-miR-152, hsa-miR-24 (52), and hsa-miR-21 (53). The data in the current study demonstrated that cyclin D1 was the target of miRNA-494 and was downregulated in cells overexpressing miRNA-494. Consequently, the cell cycle was arrested in the G1 phase and cell proliferation was inhibited.

In summary, the present study demonstrated that NGF significantly downregulated the expression of miRNA-494 in hCECs in vitro and miRNA-494 overexpression suppressed cell proliferation by directly binding to the 3' UTR of cyclin D1. Therefore, miRNA-494 may represent a promising therapeutic target for treating corneal epithelial diseases.

\section{Acknowledgements}

We would like to thank Wentao Wang for her outstanding technical assistance. The authors were supported by grants from the Key Clinic Medicine Research Program, the Ministry of Health, China (grant no. 201302015); the National Science and Technology Research Program, the Ministry of Science and Technology, China (grant no. 2012BAI08B01); and the National Natural Science Foundation of China (grant nos. 81170817, 81200658, 81300735, 81270978, U1205025 and 81330022); Scientific Research Program, Science and Technology Commission of Shanghai Municipality, Shanghai (grant nos. 13441900900 and 13430720400); the Chinese Postdoctoral Fund (grant no. XMU135890); and the New Technology Joint Research Project in 10 Shanghai Hospitals (grant no. SHDC12014114). Sponsors/funding organizations had no role in the design or conduct of this research.

\section{References}

1. Ebendal T: Function and evolution in the NGF family and its receptors. J Neurosci Res 32: 461-470, 1992.

2. Barbacid M: Neurotrophic factors and their receptors. Curr Opin Cell Biol 7: 148-155, 1995.

3. Qi H, Li DQ, Shine HD, Chen Z, Yoon KC, Jones DB and Pflugfelder SC: Nerve growth factor and its receptor TrkA serve as potential markers for human corneal epithelial progenitor cells. Exp Eye Res 86: 34-40, 2008.

4. Qi H, Chuang EY, Yoon KC, de Paiva CS, Shine HD, Jones DB, Pflugfelder SC and Li DQ: Patterned expression of neurotrophic factors and receptors in human limbal and corneal regions. Mol Vis 13: 1934-1941, 2007.

5. Chao MV: The p75 neurotrophin receptor. J Neurobiol 25: $1373-1385,1994$

6. Lambiase A, Rama P, Bonini S, Caprioglio G and Aloe L: Topical treatment with nerve growth factor for corneal neurotrophic ulcers. N Engl J Med 338: 1174-1180, 1998.

7. Bartel DP: MicroRNAs: Genomics, biogenesis, mechanism, and function. Cell 116: 281-297, 2004.

8. Carthew RW: Gene regulation by microRNAs. Curr Opin Genet Dev 16: 203-208, 2006
9. Hwang HW and Mendell JT: MicroRNAs in cell proliferation, cell death, and tumorigenesis. Br J Cancer 96 (Suppl): R40-R44, 2007.

10. Peng H, Hamanaka RB, Katsnelson J, Hao LL, Yang W, Chandel NS and Lavker RM: MicroRNA-31 targets FIH-1 to positively regulate corneal epithelial glycogen metabolism. FASEB J 26: 3140-3147, 2012.

11. Lee SK, Teng Y, Wong HK, Ng TK, Huang L, Lei P, Cho KW, Liu Y, Zhang M, Lam DS, et al: MicroRNA-145 regulates human corneal epithelial differentiation. PLoS One 6: e21249, 2011.

12. Yu J, Peng H, Ruan Q, Fatima A, Getsios S and Lavker RM: MicroRNA-205 promotes keratinocyte migration via the lipid phosphatase SHIP2. FASEB J 24: 3950-3959, 2010.

13. Ryan DG, Oliveira-Fernandes M and Lavker RM: MicroRNAs of the mammalian eye display distinct and overlapping tissue specificity. Mol Vis 12: 1175-1184, 2006.

14. Hughes AE, Bradley DT, Campbell M, Lechner J, Dash DP, Simpson DA and Willoughby CE: Mutation altering the miR-184 seed region causes familial keratoconus with cataract. Am J Hum Genet 89: 628-633, 2011.

15. Peng H, Park JK, Katsnelson J, Kaplan N, Yang W, Getsios S and Lavker RM: microRNA-103/107 family regulates multiple epithelial stem cell characteristics. Stem Cells 33: 1642-1656, 2015.

16. Kogo R, Mimori K, Tanaka F, Komune S and Mori M: Clinical significance of miR-146a in gastric cancer cases. Clin Cancer Res 17: 4277-4284, 2011.

17. Xu B, Wang N, Wang X, Tong N, Shao N, Tao J, Li P, Niu X, Feng $\mathrm{N}$ and Zhang L, et al: MiR-146a suppresses tumor growth and progression by targeting EGFR pathway and in a p-ERK-dependent manner in castration-resistant prostate cancer. Prostate 72: 1171-1178, 2012.

18. Chen G, Umelo IA, Lv S, Teugels E, Fostier K, Kronenberger P, Dewaele A, Sadones J, Geers C and De Grève J: miR-146a inhibits cell growth, cell migration and induces apoptosis in non-small cell lung cancer cells. PLoS One 8: e60317, 2013.

19. Funari VA, Winkler M, Brown J, Dimitrijevich SD, Ljubimov AV and Saghizadeh M: Differentially expressed wound healing-related microRNAs in the human diabetic cornea. PLoS One 8: e84425, 2013

20. Hong J, Qian T, Le Q, Sun X, Wu J, Chen J, Yu X and Xu J: NGF promotes cell cycle progression by regulating D-type cyclins via PI3K/Akt and MAPK/Erk activation in human corneal epithelial cells. Mol Vis 18: 758-764, 2012

21. Lambiase A, Manni L, Bonini S, Rama P, Micera A and Aloe L: Nerve growth factor promotes corneal healing: Structural, biochemical, and molecular analyses of rat and human corneas. Invest Ophthalmol Vis Sci 41: 1063-1069, 2000.

22. García de la Torre N, Fernández-Durango R, Gómez R, Fuentes M, Roldán-Pallarés M, Donate J, Barabash A, Alonso B, Runkle I, Durán A, et al: Expression of angiogenic MicroRNAs in endothelial progenitor cells from type 1 diabetic patients with and without diabetic retinopathy. Invest Ophthalmol Vis Sci 56: 4090-4098, 2015.

23. Yoav B and Yosef H: Controlling the false discovery rate: A practical and powerful approach to multiple testing. J R Stat Soc 57: 289-300, 1995.

24. Winter J and Diederichs S: MicroRNA biogenesis and cancer. Methods Mol Biol 676: 3-22, 2011.

25. Kato H, Takahashi A and Itoyama Y: Cell cycle protein expression in proliferating microglia and astrocytes following transient global cerebral ischemia in the rat. Brain Res Bull 60: R215-R221, 2003.

26. Bonini S, Lambiase A, Rama P, Caprioglio G and Aloe L: Topical treatment with nerve growth factor for neurotrophic keratitis. Ophthalmology 107: 1347-1352, 2000.

27. You L, Kruse FE and Völcker HE: Neurotrophic factors in the human cornea. Invest Ophthalmol Vis Sci 41: 692-702, 2000.

28. Lambiase A, Sacchetti M and Bonini S: Nerve growth factor therapy for corneal disease. Curr Opin Ophthalmol 23: 296-302, 2012.

29. Cellini M, Bendo E, Bravetti GO and Campos EC: The use of nerve growth factor in surgical wound healing of the cornea. Ophthalmic Res 38: 177-181, 2006.

30. Esquenazi S, Bazan HE, Bui V, He J, Kim DB and Bazan NG: Topical combination of NGF and DHA increases rabbit corneal nerve regeneration after photorefractive keratectomy. Invest Ophthalmol Vis Sci 46: 3121-3127, 2005.

31. Lambiase A, Manni L, Rama P and Bonini S: Clinical application of nerve growth factor on human corneal ulcer. Arch Ital Biol 141: 141-148, 2003. 
32. Tan MH, Bryars J and Moore J: Use of nerve growth factor to treat congenital neurotrophic corneal ulceration. Cornea 25 : 352-355, 2006.

33. Anand P, Terenghi G, Warner G, Kopelman P, Williams-Chestnut RE and Sinicropi DV: The role of endogenous nerve growth factor in human diabetic neuropathy. Nat Med 2: 703-707, 1996.

34. Lee KF, Li E, Huber LJ, Landis SC, Sharpe AH, Chao MV and Jaenisch R: Targeted mutation of the gene encoding the low affinity NGF receptor $\mathrm{p} 75$ leads to deficits in the peripheral sensory nervous system. Cell 69: 737-749, 1992.

35. Smeyne RJ, Klein R, Schnapp A, Long LK, Bryant S, Lewin A, Lira SA and Barbacid M: Severe sensory and sympathetic neuropathies in mice carrying a disrupted Trk/NGF receptor gene. Nature 368: 246-249, 1994.

36. Zhang J, Zhang J, Liu LH, Zhou Y, Li YP, Shao ZH, Wu YJ, Li MJ, Fan YY and Shi HJ: Effects of miR-541 on neurite outgrowth during neuronal differentiation. Cell Biochem Funct 29: 279-286, 2011.

37. Lim L, Balakrishnan A, Huskey N, Jones KD, Jodari M, Ng R, Song G, Riordan J, Anderton B, Cheung ST, et al: MicroRNA-494 within an oncogenic microRNA megacluster regulates G1/S transition in liver tumorigenesis through suppression of mutated in colorectal cancer. Hepatology 59: 202-215, 2014.

38. Kim WK, Park M, Kim YK, Tae YK, Yang HK, Lee JM and Kim H: MicroRNA-494 downregulates KIT and inhibits gastrointestinal stromal tumor cell proliferation. Clin Cancer Res 17: 7584-7594, 2011.

39. Ohdaira H, Sekiguchi M, Miyata K and Yoshida K: MicroRNA-494 suppresses cell proliferation and induces senescence in A549 lung cancer cells. Cell Prolif 45: 32-38, 2012.

40. Krek A, Grün D, Poy MN, Wolf R, Rosenberg L, Epstein EJ, MacMenamin P, da Piedade I, Gunsalus KC, Stoffel M and Rajewsky N: Combinatorial microRNA target predictions. Nat Genet 37: 495-500, 2005.

41. Lan YF, Chen HH, Lai PF, Cheng CF, Huang YT, Lee YC, Chen TW and Lin H: MicroRNA-494 reduces ATF3 expression and promotes AKI. J Am Soc Nephrol 23: 2012-2023, 2012.

42. Liu L, Jiang Y, Zhang $H$, Greenlee AR and Han Z: Overexpressed miR-494 down-regulates PTEN gene expression in cells transformed by anti-benzo(a)pyrene-trans-7,8-dihydrodiol-9,10-epoxide. Life Sci 86: 192-198, 2010.

43. Romano G, Acunzo M, Garofalo M, Di Leva G, Cascione L, Zanca C, Bolon B, Condorelli G and Croce CM: MiR-494 is regulated by ERK1/2 and modulates TRAIL-induced apoptosis in non-small-cell lung cancer through BIM down-regulation. Proc Natl Acad Sci USA 109: 16570-16575, 2012.
44. Tominaga K, Srikantan S, Lee EK, Subaran SS, Martindale JL, Abdelmohsen K and Gorospe M: Competitive regulation of nucleolin expression by HuR and miR-494. Mol Cell Biol 31: 4219-4231, 2011

45. Anbazhagan AN, Priyamvada S, Kumar A, Maher DB, Borthakur A, Alrefai WA, Malakooti J, Kwon JH and Dudeja PK: Translational repression of SLC26A3 by miR-494 in intestinal epithelial cells. Am J Physiol Gastrointest Liver Physiol 306: G123-G131, 2014.

46. Yamamoto H, Morino K, Nishio Y, Ugi S, Yoshizaki T, Kashiwagi A and Maegawa H: MicroRNA-494 regulates mitochondrial biogenesis in skeletal muscle through mitochondrial transcription factor A and Forkhead box j3. Am J Physiol Endocrinol Metab 303: E1419-E1427, 2012.

47. Matsushime H, Quelle DE, Shurtleff SA, Shibuya M, Sherr CJ and Kato JY: D-type cyclin-dependent kinase activity in mammalian cells. Mol Cell Biol 14: 2066-2076, 1994.

48. Quelle DE, Ashmun RA, Shurtleff SA, Kato JY, Bar-Sagi D, Roussel MF and Sherr CJ: Overexpression of mouse D-type cyclins accelerates G1 phase in rodent fibroblasts. Genes Dev 7: 1559-1571, 1993.

49. Matsushime H, Ewen ME, Strom DK, Kato JY, Hanks SK, Roussel MF and Sherr CJ: Identification and properties of an atypical catalytic subunit (p34PSK-J3/cdk4) for mammalian D type G1 cyclins. Cell 71: 323-334, 1992.

50. Johnson DG and Walker CL: Cyclins and cell cycle checkpoints. Annu Rev Pharmacol Toxicol 39: 295-312, 1999.

51. Li P, Liu Y, Yi B, Wang G, You X, Zhao X, Summer R, Qin Y and Sun J: MicroRNA-638 is highly expressed in human vascular smooth muscle cells and inhibits PDGF-BB-induced cell proliferation and migration through targeting orphan nuclear receptor NOR1. Cardiovase Res 99: 185-193, 2013.

52. Rio-Machin A, Ferreira BI, Henry T, Gómez-López G, Agirre X, Alvarez S, Rodriguez-Perales S, Prosper F, Calasanz MJ, Martínez J, et al: Downregulation of specific miRNAs in hyperdiploid multiple myeloma mimics the oncogenic effect of IgH translocations occurring in the non-hyperdiploid subtype. Leukemia 27: 925-931, 2013.

53. Zhou X, Ren Y, Moore L, Mei M, You Y, Xu P, Wang B, Wang G, Jia Z, Pu P, et al: Downregulation of miR-21 inhibits EGFR pathway and suppresses the growth of human glioblastoma cells independent of PTEN status. Lab Invest 90: 144-155, 2010. 